\title{
Reversible cerebral vasoconstriction syndrome presenting as convexity subarachnoid haemorrhage and posterior reversible encephalopathy syndrome during postpartum: a case report and literature review
}

Junliang Yuan

Beijing Chaoyang Hospital

Zejin Jia

Beijing Chaoyang Hospital

Wei Qin

Beijing Chaoyang Hospital

Wenli Hu ( $\nabla$ huwenli@sina.com )

Beijing Chaoyang Hospital Affiliated to Capital Medical University https://orcid.org/0000-0002-94439203

\section{Case report}

Keywords: Reversible cerebral vasoconstriction syndrome, convexity subarachnoid haemorrhage, posterior reversible encephalopathy syndrome

Posted Date: April 12th, 2019

DOl: https://doi.org/10.21203/rs.2.9146/v1

License: (c) (i) This work is licensed under a Creative Commons Attribution 4.0 International License. Read Full License 


\section{Abstract}

Background Reversible cerebral vasoconstriction syndrome (RCVS) is characterized by thunderclap headache and reversible cerebral vasoconstriction, with other neurologic signs and symptoms. To the best of our knowledge, there were only a few cases of RCVS presenting both as both convexity subarachnoid haemorrhage (CSAH) and posterior reversible encephalopathy syndrome (PRES). Case presentation Herein, We report a case of a 32-year-old woman with RCVS who presented with recurrent thunderclap headaches that occurred 50 days after delivery, with cSAH and PRES on magnetic resonance imaging (MRI). She had significant clinical and radiological recover with 3 months' follow-up. Conclusions The clinical coexistence of cSAH and PRES in our case with RCVS is quite rare. This case further raises the importance of the early diagnosis of RCVS, and clinical physicians should be well recognized when initial brain and vascular imaging are normal.

\section{Background}

Reversible cerebral vasoconstriction syndrome (RCVS) is quite a scarce clinical-radiological syndrome that can lead to death. It is with the characteristics of recurrent severe thunderclap headaches with or without focal neurological deficits and diffuse segmental constriction of the cerebral arteries which is usually spontaneously reversible within 3 months [1]. This recognized syndrome is increasingly supposedly due to a transient disturbance in the control of cerebral vascular tone with sympathetic overactivity. More than half of the cases occur after exposure to vasoactive substances or during postpartum [2]. More than one third of cases could develop ischemic and or hemorrhagic complications such as non-traumatic convexity subarachnoid haemorrhage (CSAH), posterior reversible encephalopathy syndrome (PRES), intracerebral haemorrhage (ICH) and even ischemic stroke. Acute non-traumatic cSAH is increasingly recognized with at high risk of future symptomatic ICH [3], which may be attributed to a great number of etiologies. It was reported that besides intracranial aneurysm, RCVS and cerebral amyloid angiopathy (CAA) were also the common causes of CSAH [4-6]. As for posterior reversible encephalopathy syndrome (PRES), it is a clinico-radiological syndrome characterized by headache, seizures, mental disorder, visual loss and vasogenic edema predominantly affecting the posterior lobes of the brain [7]. The underlying pathogenesis of RCVS remains poorly understood, however, a spectrum of vascular dysregulation, oxidative stress, disruption of the blood-brain barrier, and endothelial dysfunction may be the main causes of RCVS.

However, as far as we know, there were only a few cases of RCVS presenting both with CSAH and PRES documented in former literatures. Therefore, we herein reported a rare case of postpartum female with RCVS presenting with CSAH and PRES, with complete recovery of neurological and imaging findings.

\section{Case Presentation}

A 32-year-old woman suddenly developed a severe thunderclap headache during the course of defecation, with a higher level blood pressure $(180 / 100 \mathrm{mmHg})$. She was suffered from spontaneous 
vaginal delivery 50 days ago. Two days later, recurrent severe thunderclap headaches reoccurred induced by a cough. Neurological examinations revealed no abnormalities. Laboratory examinations were within normal limits.

Three days after the first episode of headache, her initial computed tomography (CT) of the brain suggested bilateral parieto-occipital cortexes of cSAH, especially lateralized to the right hemisphere (Figure 1). At the same time, magnetic resonance imaging (MRI) of the brain also revealed bilateral cSAH and high-intensity lesions located in parieto-occipital cortices suggestive of PRES (Figure 2). However, magnetic resonance angiography (MRA) revealed no abnormalities. Digital subtraction angiography was unremarkable six days after the first episode of headache. Transcranial Doppler also showed elevated velocities in the bilateral middle cerebral artery, the right anterior cerebral artery, the left cerebral posterior cerebral artery and the left internal carotid artery 14 days after the first episode of headache.

After admission, she was treated with nimodipine $60 \mathrm{mg} 4$ hourly/day, and controlled the blood pressure. She was discharged with not any clinical syndrome after two weeks. Repeated brain MRA showed the absolute resolution of the vasoconstriction three months later.

Fourteen days after the first episode of headache, repeat brain MRI showed complete resolution of the cSAH and high-intensity lesions in the bilateral occipital and parietal lobes (Figure 3). However, at the same time, brain MRA showed multiple segmental constrictions of the cerebral arteries (Figure 4). A clinical final diagnosis of the concurrence of RCVS associated with cSAH and PRES was performed.

\section{Discussion And Conclusions}

RCVS is a low incidence disability with a wide variety of etiologies and a wide array of symptoms. The main symptoms involve thunderclap headache, accompanied sometimes with various neurological deficits such as often complicated by ischemic or hemorrhagic strokes. Although RCVS may be spontaneous, it is often provoked by postpartum state or exposure to provocative drugs [8]. However, the clinical outcome may be severe when complicated with stroke, which may lead to death. RCVS has been reported to be the commonest cause of isolated cSAH in patients less than 60 years old [9], and more than $30 \%$ of patients with RCVS suffer from cSAH [10]. RCVS could perform haemorrhagic and ischaemic complications and sometimes occurs in concert with PRES. As for PRES, it is characterized by the acute onset of neurologic symptoms including headache, altered mental status, visual changes and seizures, with accompanying vasogenic edema.

PRES and RCVS are rare neurological disorders with complex physiopathology which has been not yet fully understood. To the best of our knowledge, the co-occurrences of RCVS and PRES have been reported in the following conditions, such as postpartum, post-transfusion, intracranial hypotension, licorice and hemolytic uremic syndrome. The co-occurrences have also found after bilateral carotid paraganglioma resection, oral contraceptive pills囚intravenous immune globulin therapy in Guillain-Barre syndrome and heart transplantation [7, 12-21]. The pathogenesis of RCVS or PRES has been poorly understood, however, autonomic dysregulation, oxidative stress, and genetic predisposition are postulated [1]. 
To data, there were only two cases reported about RCVS presenting as the coexistence of CSAH and PRES. The first case was a 53-year-old woman with RCVS, suffering from an unruptured cerebral aneurysm and presenting as CSAH, PRES and cerebral infarction [22]. Another one was a rare case of a 15-year-old girl suffered from RCVS induced by tacrolimus [23]. As for the pathophysiology of RCVS, angiogram analysis showed more severe vasoconstriction in distal versus proximal segments in all lesion types [24]. Early distal vasoconstriction was associated with lobar ICH and $\mathrm{CSAH}$, and delayed proximal vasoconstriction with infarction [24]. Also it was reported that early vasogenic cerebral edema was due to small vessels dysfunction with acute disruption of the blood-brain barrier [25]. However, the pathophysiology of hemorrhagic complications underlying in RCVS or PRES remains uncertain.

The strengths of our study were listed as follows. Firstly, our case revealed a bilateral cSAH and highintensity lesions in the bilateral parieto-occipital lobes. Our case also indicated a complete resolution after 3 months. To the best of our knowledge, only two cases have been previously described of RCVS presented as CSAH and PRES. Secondly, to date, RCVS is typically encountered during one to three weeks after delivery. However, it can also occur 6 weeks later after delivery [26]. Our case performed with RCVS 50 days after delivery, which raised the importance of the early recognition of this syndrome until 50 days after delivery.

In conclusion, CSAH and PRES are common complications of RCVS. RCVS is considered a rare syndrome with complex physiopathology [27-28]. Our case also raises awareness of the diagnosis of RCVS when initial brain and vascular imaging are normal. Early diagnosis and treatment are of great importance for a better prognosis.

\section{Abbreviations}

RCVS: Reversible cerebral vasoconstriction syndrome; cSAH: convexity subarachnoid haemorrhage; PRES: posterior reversible encephalopathy syndrome; CAA: cerebral amyloid angiopathy (CAA); CT: computed tomography; MRI: magnetic resonance imaging; ICH, symptomatic intracerebral haemorrhage; MRA: magnetic resonance angiography.

\section{Declarations}

\section{Acknowledgements}

We thank SKW who performed and interpreted the MRI studies.

\section{Funding}

This work was supported by the National Natural Science Foundation of China (81301016) and the Beijing Municipal Administration of Hospitals Incubating Program (PX2019009). The two findings help us data collection, analysis, and interpretation of data.

\section{Availability of Data and Materials}


Not applicable

\section{Authors' contributions}

JLY and ZJJ examined, evaluated the patient and drafted the manuscript. WQ and WLH participated in the design of the case-report and helped to draft the manuscript. All authors read and approved the final manuscript.

\section{Ethics Approval and Consent to Participate}

The study was approved by the Institutional Ethical Committee of Beijing Chaoyang Hospital, Capital Medical University.

\section{Consent for publication}

Written informed consent was obtained from the patient for publication of this Case Report and any accompanying images. A copy of the written consent is available for review by the Editor of this journal.

\section{Competing interests}

The authors declare that they have no competing interests

\section{References}

1. Cappelen-Smith C, Calic Z, Cordato D. Reversible Cerebral Vasoconstriction Syndrome: Recognition and Treatment. Curr Treat Options Neurol. 2017, 19: 21.

2. Ducros A. Reversible cerebral vasoconstriction syndrome. Handb Clin Neurol. 2014, 121: 1725-41.

3. Wilson D, Hostettler IC, Ambler G, Banerjee G, Jager HR, Werring DJ. Convexity subarachnoid haemorrhage has a high risk of intracerebral haemorrhage in suspected cerebral amyloid angiopathy. $J$ Neurol. 2017, 264: 664-73.

4. Chertcoff A, Bandeo L, Pantiu F, Cejas LL, Pacha S, Roca CU, et al. Convexity subarachnoid hemorrhage: clinical features and etiology of an Argentinian cohort. Arq Neuropsiquiatr. 2017, 75: 858-61.

5. Charidimou A, Boulouis G, Fotiadis P, Xiong L, Ayres AM, Schwab KM, et al. Acute convexity subarachnoid haemorrhage and cortical superficial siderosis in probable cerebral amyloid angiopathy without lobar haemorrhage. J Neurol Neurosurg Psychiatry. 2018, 89: 397-403.

6. Khurram A, Kleinig T, Leyden J. Clinical associations and causes of convexity subarachnoid hemorrhage. Stroke. 2014, 45: 1151-53.

7. Chatterjee N, Domoto-Reilly K, Fecci PE, Schwamm LH, Singhal AB. Licorice-associated reversible cerebral vasoconstriction with PRES. Neurology. 2010, 75: 1939-41. 
8. Jacoby N, Kaunzner U, Dinkin M, Safdieh J. Diagnosing RCVS Without the CV: The Evolution of Reversible Cerebral Vasoconstriction Syndrome. Neurohospitalist. 2016, 6: NP1-4.

9. Arrigan MT, Heran MKS, Shewchuk JR. Reversible cerebral vasoconstriction syndrome: an important and common cause of thunderclap and recurrent headaches. Clin Radiol. 2018, 73: 417-27.

10. Muehlschlegel S, Kursun O, Topcuoglu MA, Fok J, Singhal AB. Differentiating reversible cerebral vasoconstriction syndrome with subarachnoid hemorrhage from other causes of subarachnoid hemorrhage. JAMA Neurol. 2013, 70: 1254-60.

11. Brady E, Parikh NS, Navi BB, Gupta A, Schweitzer AD. The imaging spectrum of posterior reversible encephalopathy syndrome: A pictorial review. Clin Imaging. 2018, 47: 80-9.

12. Agarwal R, Davis C, Altinok D, Serajee FJ. Posterior reversible encephalopathy and cerebral vasoconstriction in a patient with hemolytic uremic syndrome. Pediatr Neurol. 2014, 50: 518-21.

13. Akazawa Y, Inaba Y, Hachiya A, Motoki N, Matsuzaki S, Minatoya K, et al. Reversible cerebral vasoconstriction syndrome and posterior reversible encephalopathy syndrome in a boy with Loeys-Dietz syndrome. Am J Med Genet A. 2015, 167A: 2435-39.

14. Ban SP, Hwang G, Kim CH, Kwon OK. Reversible cerebral vasoconstriction syndrome combined with posterior reversible encephalopathy syndrome after heart transplantation. J Clin Neurosci. 2017, 42: 11821.

15. Doss-Esper CE, Singhal AB, Smith MS, Henderson GV. Reversible posterior leukoencephalopathy, cerebral vasoconstriction, and strokes after intravenous immune globulin therapy in guillain-barre syndrome. J Neuroimaging. 2005, 15: 188-92.

16 Feil K, Forbrig R, Thaler FS, Conrad J, Heck S, Dorn F, et al. Reversible cerebral vasoconstriction syndrome and posterior reversible encephalopathy syndrome associated with intracranial hypotension. Neurocrit Care. 2017, 26: 103-8.

17. Ito Y, Niwa H, lida T, Nagamatsu M, Yasuda T, Yanagi T, et al. Post-transfusion reversible posterior leukoencephalopathy syndrome with cerebral vasoconstriction. Neurology. 1997, 49: 1174-5.

18. Lemmens R, Smet S, Wilms G, Demaerel P, Thijs V. Postpartum RCVS and PRES with normal initial imaging findings. Acta Neurol Belg. 2012, 112: 189-92.

19. Mathis S, Palazzo P, Lamy M, Ragot S, Lapeyrie S, Ricco JB, et al. Posterior reversible encephalopathy syndrome and reversible cerebral vasoconstriction syndrome after bilateral carotid paraganglioma resection: A case report. Cephalalgia. 2017, 37: 89-93.

20. Ruiz Lopez N, Cano Hernandez B, Balbas Alvarez S. Posterior reversible encephalopathy syndrome and cerebrovascular constriction syndrome in the differential diagnosis of post-partum headaches. Rev 
Esp Anestesiol Reanim. 2016, 63: 116-121.

21. Soo Y, Singhal AB, Leung T, Yu S, Mak H, Hao Q, et al. Reversible cerebral vasoconstriction syndrome with posterior leucoencephalopathy after oral contraceptive pills. Cephalalgia. 2010, 30: 42-5.

22. Noda K, Fukae J, Fujishima K, Mori K, Urabe T, Hattori N, et al. Reversible cerebral vasoconstriction syndrome presenting as subarachnoid hemorrhage, reversible posterior leukoencephalopathy, and cerebral infarction. Intern Med. 2011, 50: 1227-33.

23. Kodama S, Mano T, Masuzawa A, Hirata Y, Nagasako Y, Koshi Mano K, et al. Tacrolimus-Induced Reversible Cerebral Vasoconstriction Syndrome with Delayed Multi-Segmental Vasoconstriction. J Stroke Cerebrovasc Dis. 2017, 26: e75-e77.

24. Topcuoglu MA, Singhal AB. Hemorrhagic Reversible Cerebral Vasoconstriction Syndrome: Features and Mechanisms. Stroke. 2016, 47: 1742-7.

25. Mrozek S, Lonjaret L, Jaffre A, Januel AC, Raposo N, Boetto S, et al. Reversible Cerebral Vasoconstriction Syndrome with Intracranial Hypertension: Should Decompressive Craniectomy Be Considered?. Case Rep Neurol. 2017, 9: 6-11.

26. Miller TR, Shivashankar R, Mossa-Basha M, Gandhi D. Reversible Cerebral Vasoconstriction Syndrome, Part 1: Epidemiology, Pathogenesis, and Clinical Course. Am J Neuroradiol. 2015, 36: 1392-9.

27. Kato Y, Hayashi T, Mizuno S, Horiuchi Y, Ohira M, Tanahashi N, et al. Triptan-induced Reversible Cerebral Vasoconstriction Syndrome: Two Case Reports with a Literature Review. Intern Med. 2016, 55: 3525-8.

28. Pop A, Carbonnel M, Wang A, Josserand J, Auliac SC, Ayoubi JM. Posterior reversible encephalopathy syndrome associated with reversible cerebral vasoconstriction syndrome in a patient presenting with postpartum eclampsia: a case report. J Gynecol Obstet Hum Reprod. 2019, S2468-7847:30541-5

\section{Figures}



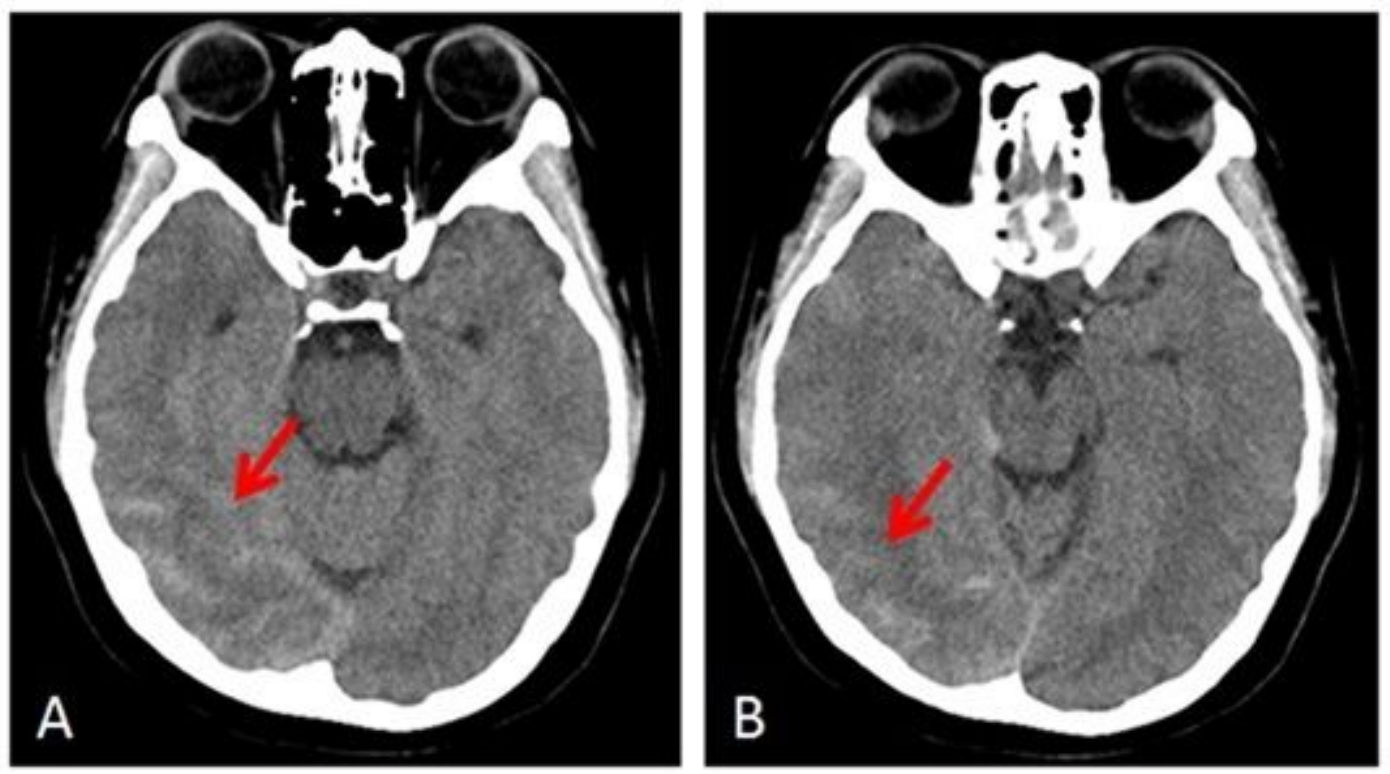

Figure 1

Brain CT suggested suggested bilateral parieto-occipital cortexes of cSAH, especially lateralized to the right hemisphere.
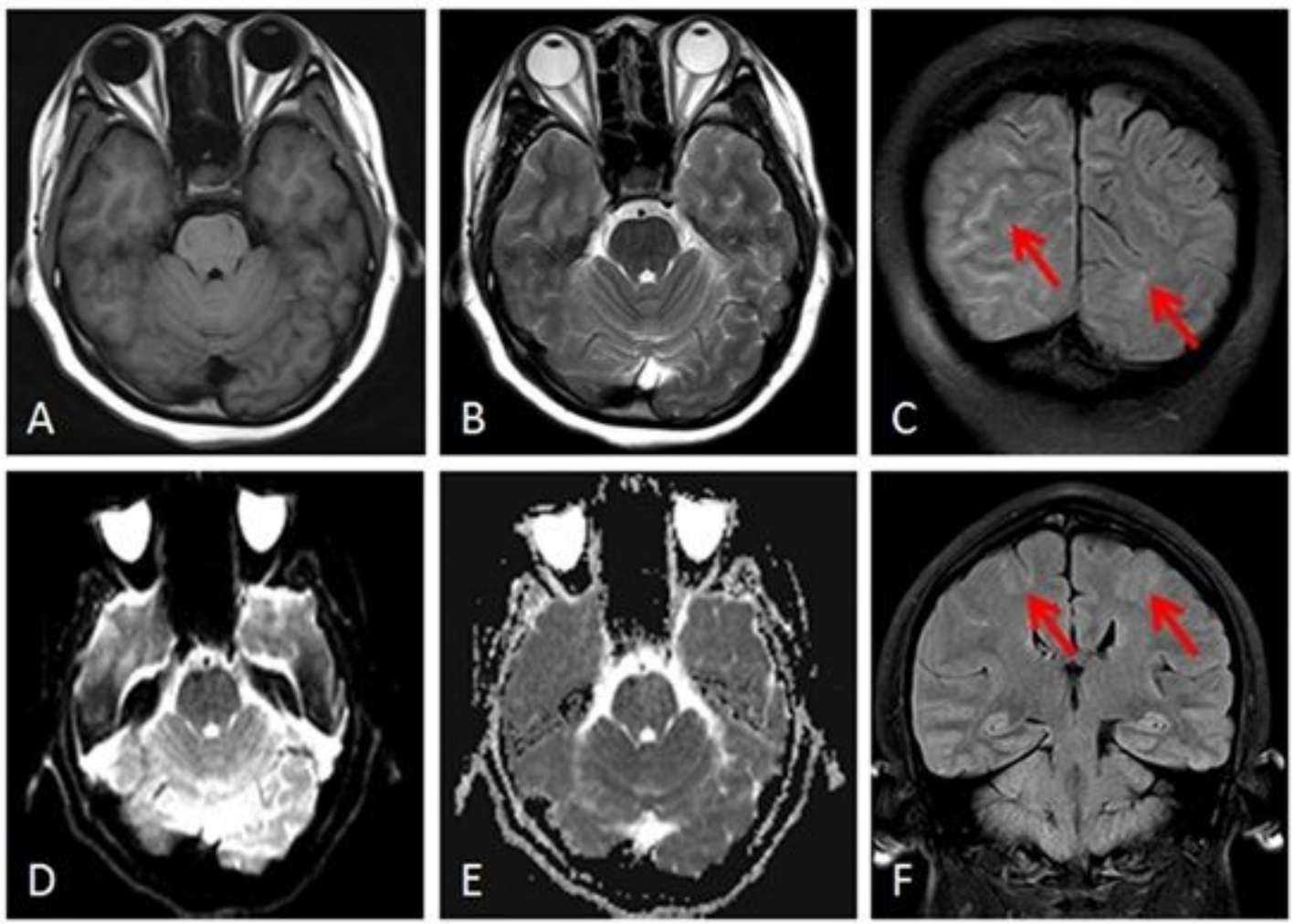

Figure 2

Brain MRI revealed bilateral CSAH and high-intensity lesions located in parieto-occipital cortices suggestive of PRES 

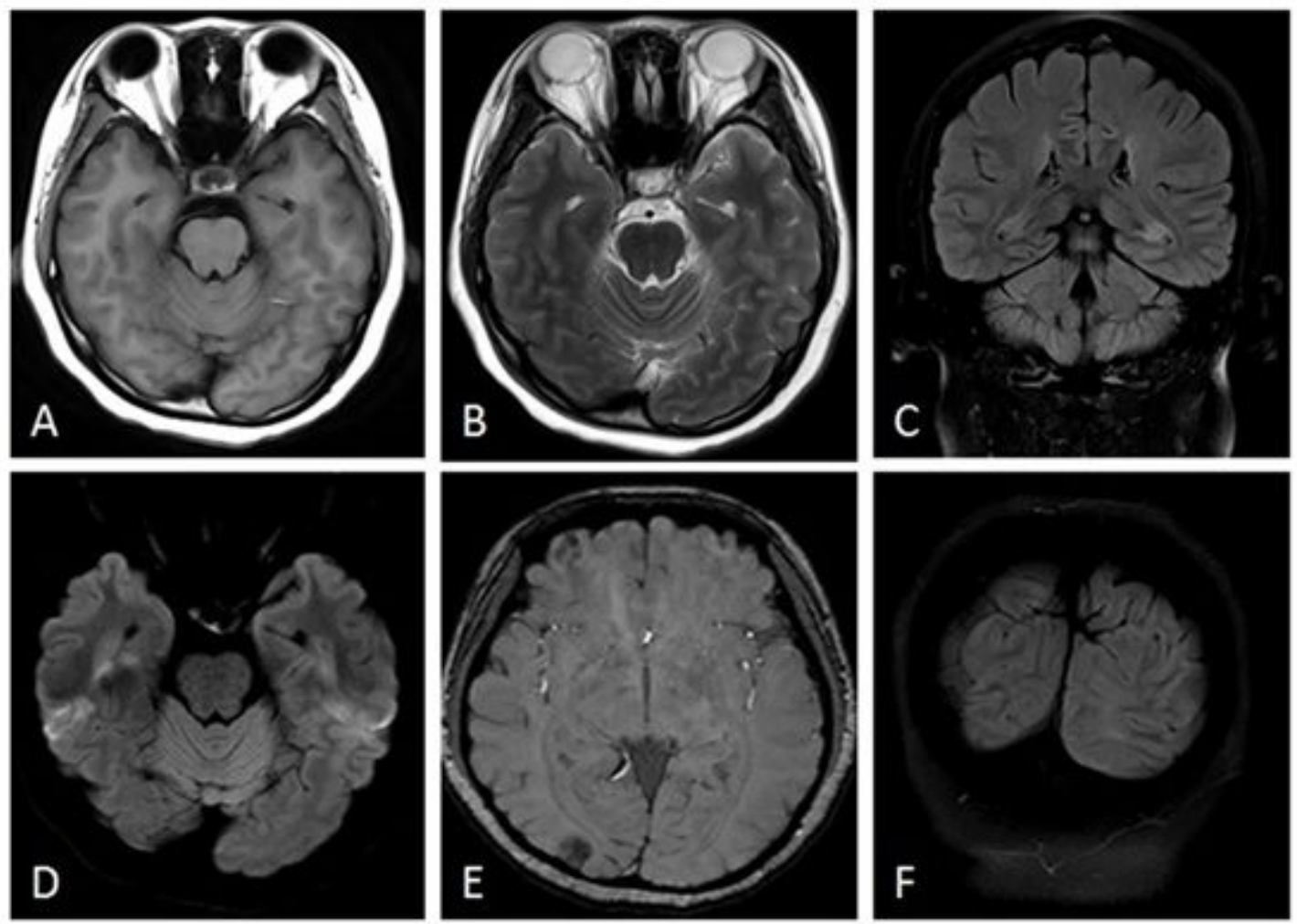

\section{Figure 3}

The brain MRI indicated complete resolution of the cSAH and high-intensity lesions in bilateral parietooccipital lobes 14 days after the first episode of headache.

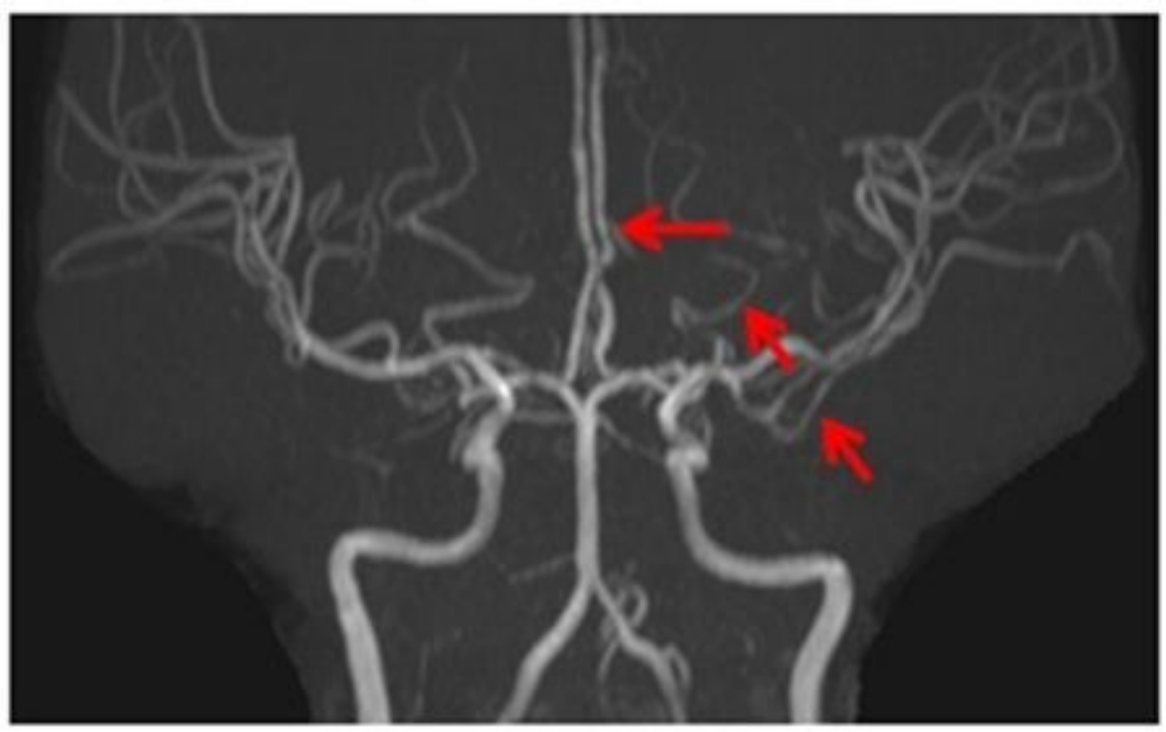

\section{Figure 4}

The brain MRA showed multiple segmental constrictions of the cerebral arteries 14 days after the first episode of headache. 